UCRL-JC-131963

Preprint

\title{
Design and Performance of the Main Amplifier System for the National Ignition Facility
}

C. Marshall, A. Erlandson, J. Horvath, K. Jancaitis, D. Larson, J. Lawson, K. Manes, E. Moor, S. Payne, L. Pedrotti, M. Rotter, S. Sutton, L. Zapata, J. Beullier, E. Grebot,J. Guenet, M.Guenet, G. LeTouze, X. Maille, T. Mengue, and S. Seznec

This paper was prepared for submittal to Fourteenth Topical Meeting on Advanced Solid-State Lasers Boston, MA

Jan. 31-Feb.3, 1999

February 16, 1999

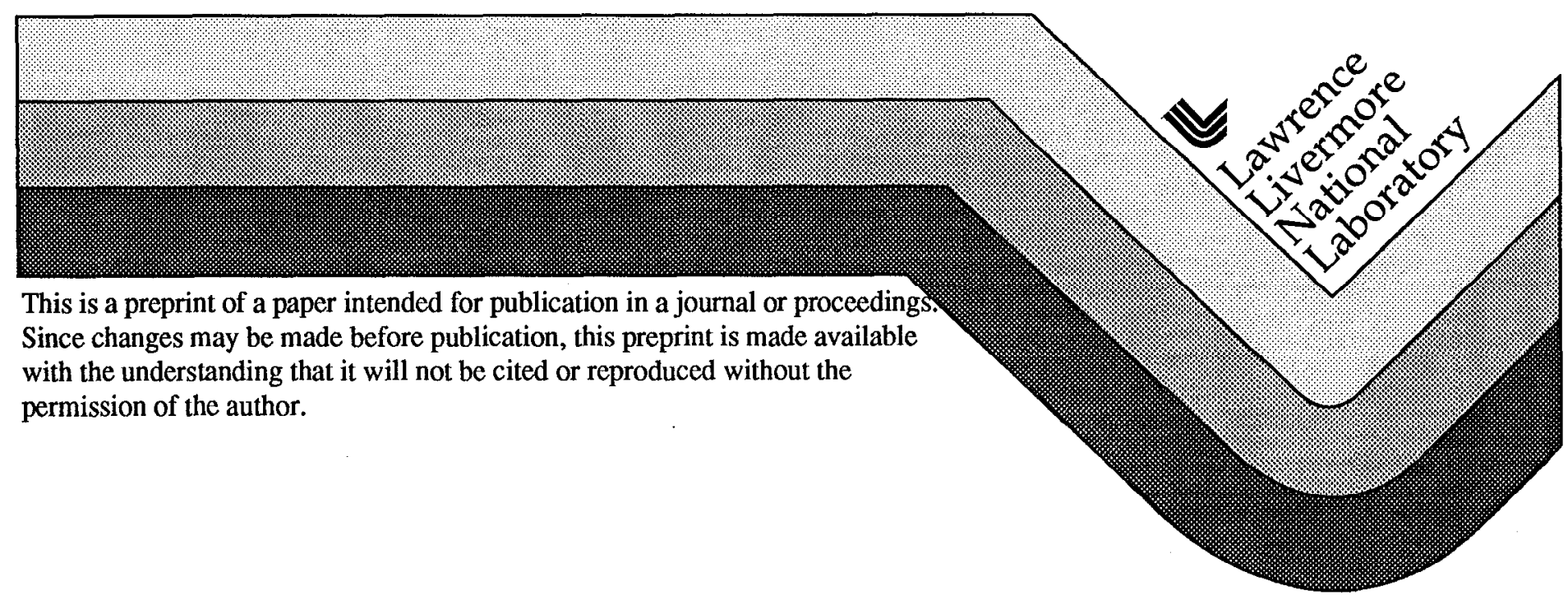




\section{DISCLAIMER}

This document was prepared as an account of work sponsored by an agency of the United States Government. Neither the United States Government nor the University of Califomia nor any of their employees, makes any warranty, express or implied, or assumes any legal liability or responsibility for the accuracy, completeness, or uscfulness of any information, apparatus, product, or process discloscd, or represents that its use would not infringe privately owned rights. Reference herein to any specific commercial product, process, or service by trade name, trademark, manufacturer, or otherwise, does not nccessarily constitute or imply its cndorsement, recommendation, or favoring by the United States Government or the University of Califomia. The views and opinions of authors expressed herein do not necessarily state or reflect those of the United States Government or the University of Califomia, and shall not be used for advertising or product endorsement purposes. 


\title{
Design and Performance of the Main Amplifier System for the National Ignition Facility
}

\author{
C. Marshall, A. Erlandson, J. Horvath, K. Jancaitis, D. Larson, J. Lawson, K. Manes, \\ E. Moor, S. Payne, L. Pedrotti, M. Rotter, S. Sutton and L. Zapata \\ Lawrence Livermore National Laboratory \\ P.O. Box 808 \\ Livermore, $C A 94551$ \\ (925) 422-9781 \\ marshall14@llnl.gov
}

\author{
J. Bcullier, E. Grebot, J. Gucnet, M. Guenet, G. LeTouze, \\ $X$. Maille, T. Mengue and S. Seznec, \\ Centre d'Etudes de Limeil-Valenton \\ 94195 Villeneuve St Georges Cedex \\ Vallenton, France
}

\begin{abstract}
This paper describes the design and performance of flashlamp-pumped, $\mathrm{Nd}$ :glass. Brewster-angle slab amplifiers intended to be deployed in the National Ignition Facility (NIF). To verify performance, we tested a full-size, three-slab-long, NIF prototype amplifier, which we believe to be the largest flashlamp-pumped Nd:glass amplifier ever assembled. Like the NIF amplifier design, this prototype amplifier had eight $40-\mathrm{cm}$-square apertures combined in a four-aperture-high by two-aperture-wide matrix. Specially-shaped reflectors, anti-reflective coatings on the blastshields, and preionized flashlamps were used to increase storage efficiency. Cooling gas was flowed over the flashlamps to remove waste pump heat and to accelerate thermal wavefront recovery.

The prototype gain results are consistent with model predictions and provide high confidence in the final engineering design of the NIF amplifiers. Although the dimensions, internal positions, and shapes of the components in the NIF amplifiers will be slightly different from the prototype, these differences are small and should produce only slight differences in amplifier performance.
\end{abstract}

\section{Introduction}

The National Ignition Facility, now being built for the US Department of Energy at Lawrence Livermore National Laboratory, will use a 192-beam, 1.8MJ laser for inertial confinement fusion (ICF) experiments [1]. The major laser component in the NIF will be the flashlamp-pumped Nd:glass amplifiers, which must provide sufficient gain and stored energy to meet requirements for laser energy and power while adding minimal wavefront distortion to the laser beams. The NIF amplifiers differ from those used in previous ICF laser systems mainly in their overall scale and packaging. Fig. 1 shows a two-slab-long, $4 \times 2$ NIF amplifier module, where the nxm designation denotes the number (height $\mathrm{x}$ width) of parallel amplifying channels or beam apertures that are combined. The NIF amplifiers use 40$\mathrm{cm}$-square apertures, which are near the practical size limit imposed by amplified spontaneous emission (ASE) that depumps the laser slabs and limits gain. Large aperture size reduces system costs by reducing 
the number of laser beams needed to produce the required energy on target. Previously, the largest amplifiers constructed were the $2 \times 2$ Beamlet amplifiers, which combined only four $40-\mathrm{cm}-\mathrm{square}$ apertures [2].

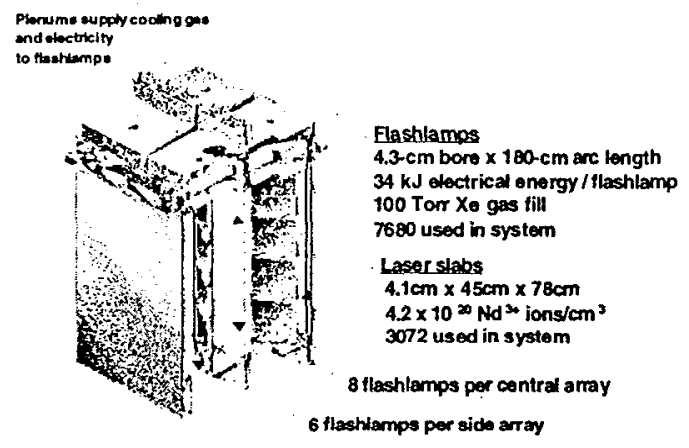

Fig. 1. A two-slab-long, $4 \times 2$ NIF amplifier module.

Amplifiers with combined beams were first proposed by LLNL in 1978 as a way to reduce the cost of MJ-class fusion laser systems [3]. Combining beams in a single enclosure reduces costs in three ways: 1) by making amplifiers more compact, thereby reducing the size and cost of the building; 2) by increasing pumping efficiency, thereby reducing the size and cost of the power-conditioning system; and 3) by reducing the number of internal amplifier parts. The NIF design achieves considerable cost savings by making the NIF amplifiers larger than the Beamlet amplifiers. Similar amplifiers will be used in the Laser Megajoule (LMJ), a 240-beam laser system now being developed and designed by the French Commissariat a l'Energie Atomique (CEA).

This paper describes the design and performance of the NIF amplifiers. Following this introduction, section two presents the NIF amplifier design while touching on amplifier performance issues and requirements; section three describes the prototype amplifier design; section four describes equipment used to measure optical pcrformance; section five compares model predictions with measurement results; and section six offers conclusions and a summary.

\section{NIF Amplifier Design}

\section{A. Pump-cavity Design}

The NIF amplifiers provide optical gain at the $1.053 \mu \mathrm{m}$ wavelength by using neodymium-doped, phosphate glass, rectangular laser slabs oriented at Brewster's angle with respect to the beam, to eliminate reflection losses. The slabs have absorbing glass edge claddings to prevent internal parasitic laser oscillation. Each slab holder supports four slabs, one stacked above the other. Central flashlamps cassettes pump slabs in both directions, while side flashlamp cassettes with large silver reflectors pump slabs in one direction. Glass blastshields, placed between the flashlamps and the laser slabs, serve three purposes: 1) they prevent acoustic waves generated by the flashlamps from propagating into the beam path and causing wavefront distortion; 2) they provide a contamination barrier between the flashlamp cavity and the critical slab cavity; and 3) they form one wall of the channel used for flowing cooling gas around the flashlamps. Fig. 2 shows a plan view of a single NIF amplifier slab column that illustrates the arrangement of the slabs, flashlamps, blastshields, and reflectors.

The NIF amplifier design is characterized by a number of key features. The $4.3 \mathrm{~cm}$-bore $\mathrm{x}$ $180 \mathrm{~cm}$-arc length flashlamps are energized by an electrical pulse with a duration of $360 \mu \mathrm{s}$. The 
neodymium ions in the laser slabs are optically excited by the flashlamp light to produce a peak gain coefficient of about $5.0 \% / \mathrm{cm}$, averaged through all slabs in the chain. The transverse gain uniformity is determined by the distribution of flashlamp light across the slab and by the effect of amplified spontaneous emission (ASE). In large slabs such as the NIF's, which measure $4.1 \mathrm{~cm} \times 45.8 \mathrm{~cm} \times$ $80.9 \mathrm{~cm}$, ASE preferentially depletes the gain near the slab's ends because this position has the longest path length for internal amplification $[2,4,5]$. The specified peak-to-average ratio for the gain coefficient, evaluated across the chain aperture, is less than 1.05. Pump-induced wavefront distortion can occur from disk bending produced by prompt heating of the laser slab by flashlamp light, which is imbalanced from one side of the slab to the other. The total prompt pump-induced wavefront distortion produced by the entire amplifier chain is specified to be less than six waves, so that the distortions can be corrected with a deformable mirror provided in each NIF laser chain.

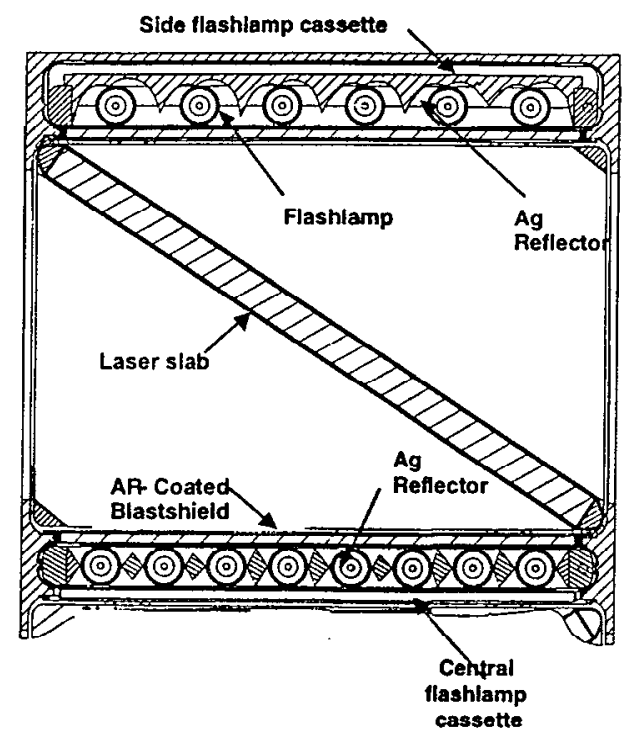

Fig. 2. Plan view of the NIF amplifier pump cavity.

The NIF amplifiers use several features to increase efficiency. The side flashlamp arrays use silver reflectors with involute reflector shapes, which are designed to reflect flashlamp light toward the laser slabs while returning little flashlamp light back to the absorbing flashlamp plasma. Compared with flat reflectors, the involute reflectors reduce the flashlamp electrical energy required to meet the gain requirement by $\sim 15 \%$. Additional reductions in flashlamp electrical energy are achieved by using sol-gel anti-reflective (AR) coatings on both sides of the blastshields (7\%); and by preionizing the flashlamps with weak electrical pulses delivered several hundred microseconds before the main pulse (10\%). Preionization causes the flashlamp arc to develop more uniformly and increases the electrical-to-optical conversion efficiency of the flashlamp plasma. Overall, the predicted storage efficiency of the NIF amplifiers is $3.8 \%$, which is significantly higher than in previous ICF lasers $(3.0 \%$ and $1.8 \%$ for the Beamlet and Nova amplifiers, respectively)[2]. Storage efficiency is defined as the total extractable energy stored in the laser slabs divided by the electrical energy delivered to the flashlamps. The NIF pump cavity design also uses skewed diamond-shaped reflectors in the central flashlamp arrays, which improve gain uniformity by directing flashlamp light to specified regions of the laser slabs.

Waste pump heat causes residual thermal wavefront distortions that persist for many hours after each shot. A principal cause of the distortions are thermal gradients in the laser slabs set up by differences between the heating and cooling rates of the laser slab and its edge cladding. Additional distortion can be caused by convection currents set up by temperature differences between laser slabs, 
blastshields, and reflectors. The slab distortions tend to be slowly-varying, low-order distortions that are largely correctable with a deformable mirror. Gas distortions, however, have high spatial frequencies and are more rapidly varying, making them difficult to correct.

To accelerate the thermal recovery rate, the NIF flashlamps will be actively cooled by flowing gas. Flashlamp cooling is effective since some $60 \%$ of the pump waste heat resides in the flashlamp envelopes immediately after a shot. Although water cooling has been successfully used to accelerate the shot rate of the Omega Laser at the University of Rochester [6], gas cooling was chosen for the NIF to eliminate water-jacket tubes and to leave more room for efficiency-enhancing reflectors. NIF flashlamp cooling system will provide gas flow rates of up to 20 cubic feet per minute per flashlamp, with the gas flow direction alternating between flashlamp cassettes as shown in Fig. 3. The inlet temperature of the cooling gas will be controlled over a $+-5 \mathrm{C}$ range centered about the ambient temperature with $+-0.3 \mathrm{C}$ accuracy.

The thermal wavefront distortion in the laser slabs is specified to be less than 2.2 waves, and the gas distortions are specified to add less than $5 \mu \mathrm{R}$ to the full beam divergence. Flowing roomtemperature gas over the flashlamps is expected to achieve these conditions in less than seven hours after each shot. With a one-hour period set aside for beam realignment after the amplifiers have thermally recovered, we expect to achieve an eight-hour period between laser shots. More rapid thermal recovery of the amplifiers appears feasible by slightly chilling the flashlamp cooling gas, however.

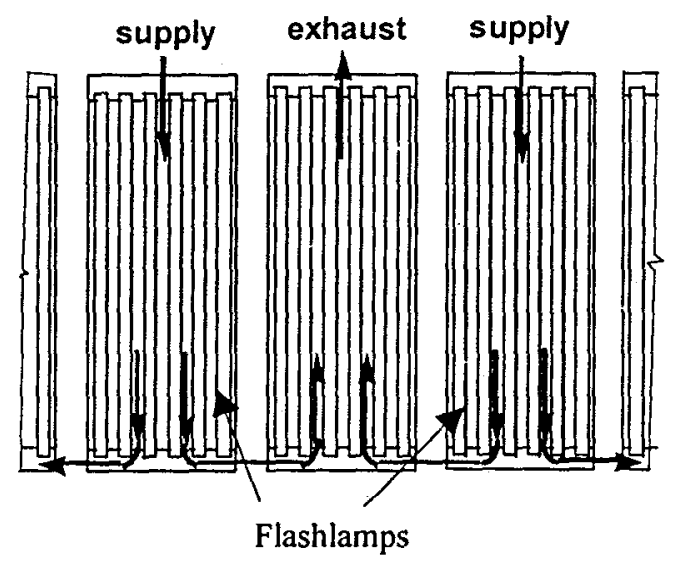

Fig. 3. By alternating the direction of cooling-gas flow through the flashlamp cassettes, cooling-gas connections can be made at the top of the amplifier, which simplifies the amplifier mechanical design.

\section{B. Mechanical Design}

The large scale of the NIF amplifiers requires new mechanical designs that allow convenient assembly and maintenance. Accordingly, the NIF amplifiers use a modular design in which the most critical components, including the flashlamps, laser slabs, and reflectors, are mounted in line-replaceable units or cassettes that can be readily inserted or removed without disturbing their neighbors [7]. See Fig. 4.

Installation and removal of flashlamp cassettes and four-high slab cassettes is accomplished by using sealed maintenance carts that access the bottom of the amplifiers. The cassettes are inserted and removed from their enclosure, called the frame assembly unit, which is supported by top plates mounted to an overhead support structure. Plenums distribute electricity and cooling gas to the flashlamps from the top, through holes in the top plate. 


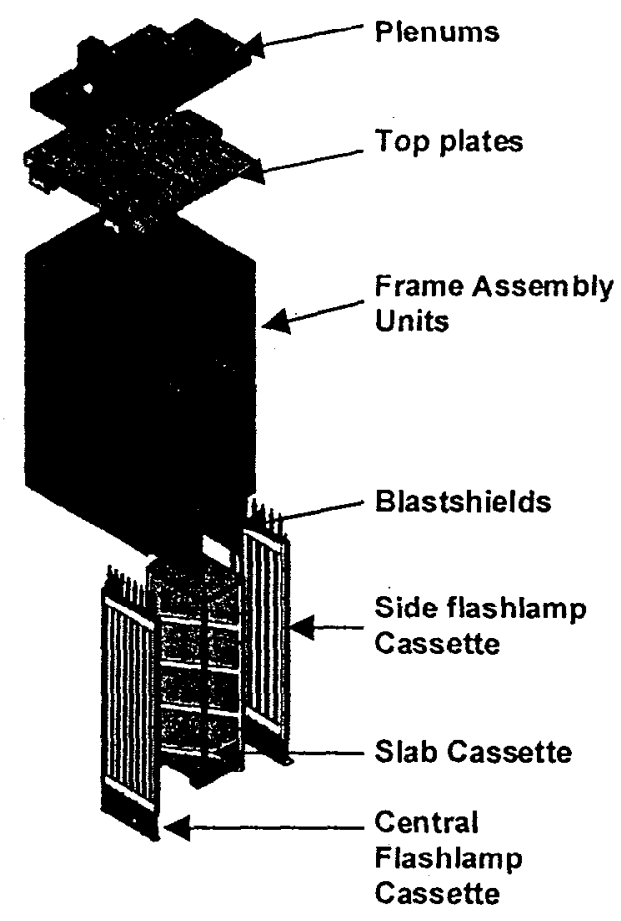

Fig. 4. The NIF amplifiers use a modular design.

Each NIF $4 \times 2$ beam bundle uses an eleven-slab-long main amplifier that the beam passes four times, and a five-slab-long power amplifier that the beam passes twice. Assembly of these amplifiers begins in an off-line cleanroom, where the frame assembly units are cleaned and the top plates and blastshields with anti-reflective coatings are installed. A flashlamp-light-resistant polymer is used to bond the blastshields to a metal frame, and silicone inflatable seals are used to seal the metal frame to the inside of the frame assembly unit. These seals reduce leak rates between the flashlamp cavity and the slab cavity. After the blastshields have been installed, frame assembly units are bolted together to form five- and eleven-slab-long units that are transported to the laser bay where they are mounted to an overhead support structure by their top plates.

The laser slabs, reflectors, and metal parts that comprise the slab cassettes are spray-cleaned and assembled in an elevated, class-100 clean room. High cleanliness levels must be maintained, since small particles resting on the laser slabs cause damage when heated by flashlamp and laser light. Current specifications call for the laser slabs and metal surfaces to be maintained at cleanliness levels of 50 and 100, respectively, which correspond to particle-size distributions in which there are only one 50- or 100micron particle per square foot of surface area, respectively. Following assembly, the slab cassettes are lowered into a specialized clean cart. Once the cart has been moved to the laser bay, it docks to the bottom of a frame assembly unit and establishes a hermetic seal to maintain cleanliness. After the top cover of the cart and the bottom cover of the frame assembly unit have been pressed together to trap residual particles, the cover pair is moved to the side to open a passageway for the slab cassette to be raised into the frame assembly unit. Rollers mounted in the corners of the cassette guide the cassette during insertion and prevent metal-on-metal rubbing, which would generate particles. A fail-safe mechanism in the cart activates latches that hold the slab cassette in place. Slab cassettes can be removed for occasional refurbishment by reversing this installation process. Fig. 5 shows a prototype 
slab cassette cart, which has successfully completed some 50 slab-cassette transfers in our laboratory. Similar carts will be used to install and remove the NIF flashlamp cassettes and blastshields.

\section{NIF Prototype Amplifier Design}

We have built and tested a prototype amplifier at LLNL to validate key requirements prior to deployment in NIF. This prototype amplifier was extremely close to the NIF amplifier design, as it used the same size flashlamps and laser slabs and nearly the same reflector shapes. However, the prototype amplifier was slightly more compact in the direction transverse to the laser beam, due to smaller insertion clearances between the slab cassettes and the frame assembly units and thinner blastshields. Also, the prototype was slightly less compact in the direction parallel to the beam, since its frame assembly units were one slab long while the NIF frame assembly units will be two and three slabs long. Using longer frame assembly units has the advantage of eliminating a portion of the $\sim 6 \mathrm{~cm}$ gaps that exist between frame assembly units. Ray-trace codes we have developed for predicting amplifier gain show that the differences in gain and storage efficiency between the prototype amplifier and the NIF amplifiers will be slight.

The prototype amplifier was tested in both the "diamond" and " $X$ " configurations that are possible for a two-slab-long amplifier. Recently, we also began measurements on a three-slab-long amplifier. When we have completed our measurements, we will have sufficient data to estimate the gain and wavefront distributions for interior slabs and for end slabs of either type (diamond or X). Fig. 6 shows the diamond, $\mathrm{X}$, and three-slab-long amplifier configurations we have tested.

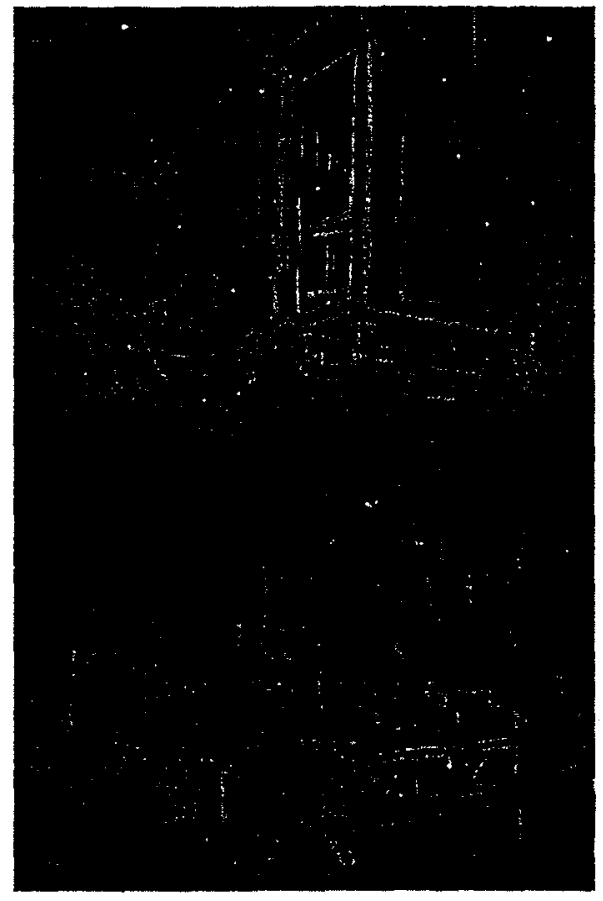

Fig. 5. Our prototype slab cassette cart shown inserting a slab cassette into the NIF prototype amplifier.

Thermocouples were used to measure temperatures at approximately 80 different locations inside the amplifier. The thermocouples were placed on three laser slabs in one of the slab cassettes, with 
holes drilled through the slabs to establish good thermal contact. Thermocouples were also placed on flashlamps, blastshields, and reflectors near the slab cassette. The purpose of the temperature measurements was to determine the initial temperature rise of the pump-cavity components and to determine cooling rates after shots.

The laser slabs in the prototype amplifier were finished from LG-770 glass made by Schott Glass and LHG-8 glass made by Hoya. Both types of laser glass had Nd ion concentrations of $4.2 \mathrm{x}$ $10^{20}$ ions $/ \mathrm{cm}^{3}$. The flashlamps were made by EG\&G and ILC Technology.
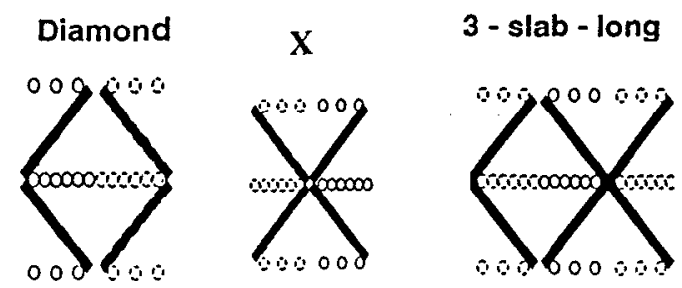

Fig. 6. We have tested the prototype amplifier in the diamond, $\mathrm{X}$, and 3-slab-long configurations.

\section{Apparatus for Gain and Wavefront Measurements}

We constructed an optical diagnostic system to perform time-resolved gain and wavefront measurements over the entire aperture of our prototype amplifier. Mcasurements were performed using a pulsed, injection seeded, single-longitudinal mode, Nd:YLF probe laser operating at $1.053 \mu \mathrm{m}$. This laser produced $80 \mathrm{~mJ}, 20$-ns-long pulses at a repetition rate of $13 \mathrm{~Hz}$. The probe-laser beam was expanded and image relayed by a series of telescopes, passed through the amplifier, reflected by a mirror, then reflected back through the amplifier and telescopes. After returning from the amplifier, a portion of the beam was sampled with a beam splitter and reflected to scientific-grade CCD cameras for gain and wavefront measurements. Fig. 7 shows a schematic diagram of our equipment.

Amplifier gain distributions were determined by calculating the ratio of the images produced by two CCD cameras (the gain reference camera and the gain probe camera) which recorded the laser beam intensity before and after the beam passed through the amplifier. Measured background contributions from the flashlamp light and amplified spontaneous emission were subtracted from the gain camera image. A correction factor for passive transmission losses was determined by firing the probe laser without firing the amplifier flashlamps. Cross hair images were used to ensure proper registration of the gain and reference camera images.

Wavefront distributions were measured by interfering the probe beam with a reference beam, which was generated with a $\sim 25-\mathrm{m}$-long single-mode optical fiber cut so that its optical length approximately matched the probe-laser path length. To increase the fringe contrast ratio, a half-wave plate and a polarizer were used to attenuate the probe laser to approximately the same intensity as the reference beam. Two cameras were used to record interferograms on successive pulses of the $13-\mathrm{Hz}$ probe laser. A Fourier-transform technique was used to calculate wavefront distributions from the interferograms [8]. The calibration of the interferometer was checked by measuring the wavefront of a known lens. From this check, we estimate the accuracy of our wavefront measurements to be +-0.02 waves rms, for both cameras. Prompt pump-induced wavefront distortion was determined by subtracting the wavefront measured at the time of peak gain from the wavefront measured $75 \mathrm{~ms}$ earlier. 


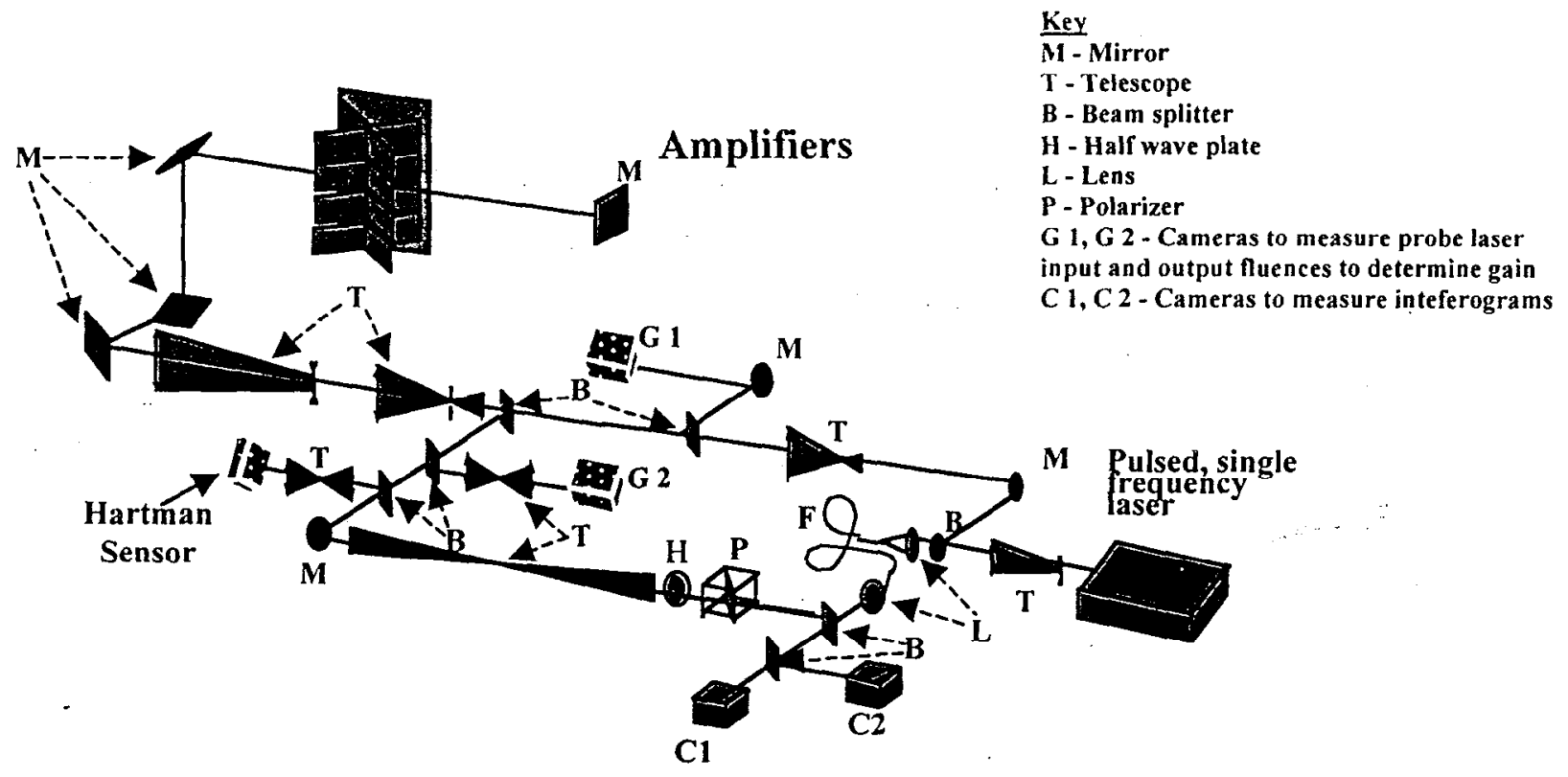

Fig. 7. We constructed a large-aperture diagnostic system to measure gain and wavefront distributions produced by the prototype amplifier.

\section{Measurement Results and Comparisons with Model Predictings}

Gain and prompt pump-induced wavefront measurements performed on the diamond and $\mathrm{X}$ amplifier configurations are in rcasonable agreement with model predictions. For example, Fig. 8 shows measured and predicted gain distributions for the bottom aperture of the $\mathrm{X}$ configuration, with the flashlamps energized with pulses close to the $34 \mathrm{~kJ}$ per lamp, $360 \mu \mathrm{s}$-long pulses anticipated for the NIF. Low flashlamp light fluences near the end of the amplifier causes gain to be lower on the right hand side of the aperture, (which is closest to the side flashlamp array). The predicted gain distribution was calculated with a $3 \mathrm{D}$ ray-trace model, which uses backwards ray-tracing from the slabs to calculate flashlamp pumping rates. This 3D model uses an empirical flashlamp emission model [9] and accounts for ASE, which preferentially depumps excited Nd ions near the slab edges [4,5]. Differences between the model predictions and measurements are less than $0.5 \% \mathrm{rms}$, for all five combinations of apertures and configurations (diamond and $\mathrm{X}$ ) modeled so far. This agreement was achieved with a single value of an adjustable parameter used to scale the flashlamp pump rate in the model. Our gain measurements and modeling are consistent with the NIF amplifiers meeting their $5 \% / \mathrm{cm}$ average gain requirement. 

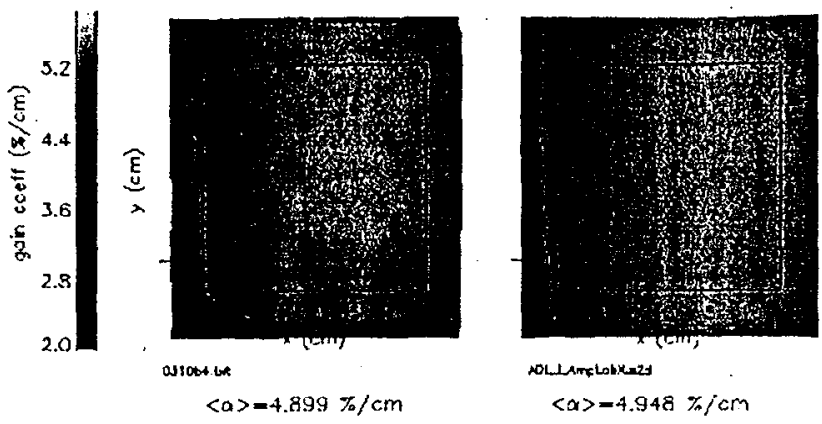

Fig. 8. Measured and predicted gain-coefficient contour plots for the $\mathrm{X}$ amplifier configuration.

Prompt pump-induced wavefront distortion measurements are also in reasonable agreement with model predictions when all pumped AMPLAB optical surfaces are included in the model. Fig. 9 compares the measured and predicted prompt pump-induced wavefront distortion for the diamond configuration, at the normal flashlamp energy of $34 \mathrm{~kJ} / \mathrm{lamp}$. The results have been normalized to a single slab pass. An imbalance in the flashlamp heating rate from one side of the slab to the other produces surface distortions, which cause the phase to be delayed by about 0.15 waves near the slab edges relative to the middle. The phase predictions were generated with a $2 \mathrm{D}$ ray-trace code which calculates the distribution of heat deposited in the laser slab by the flashlamp light, and a finite-element code which calculates the resulting surface distortions.

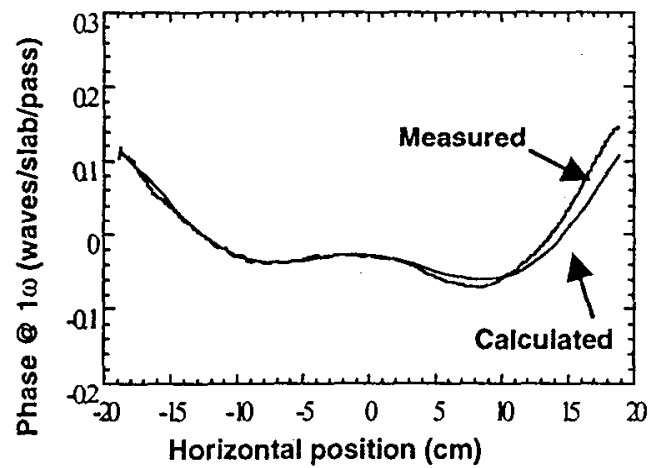

Fig. 9. Measured and predicted phase delay for the diamond amplifier configuration.

By scaling the measurements made on the diamond and $X$ slabs to the number of slab passes made in the NIF chain, we predict that the end slabs alone will produce approximately two waves of distortion, peak to valley. Tests are now underway on the three-slab-long amplifier to determine the distortion of the interior slabs experimentally.

In addition to the optical characterizations, we have also performed temperature measurements to determine the efficacy of the flashlamp cooling system. Fig. 10 shows average slab temperature versus time after a flashlamp shot, for two cases: 1) with flashlamp gas set at ambient temperature; and 2) with the flashlamp cooling gas set 0.5 degrees $\mathrm{C}$ below ambient temperature. Our data shows that the average slab temperature recovers to within $\sim 0.1 \mathrm{C}$ of the ambient temperature in about nine hours using ambient-temperature cooling gas, and in about four hours using slightly chilled gas. Efforts to measure thermal wavefront distortions and to optimize the cooling process are in progress. 


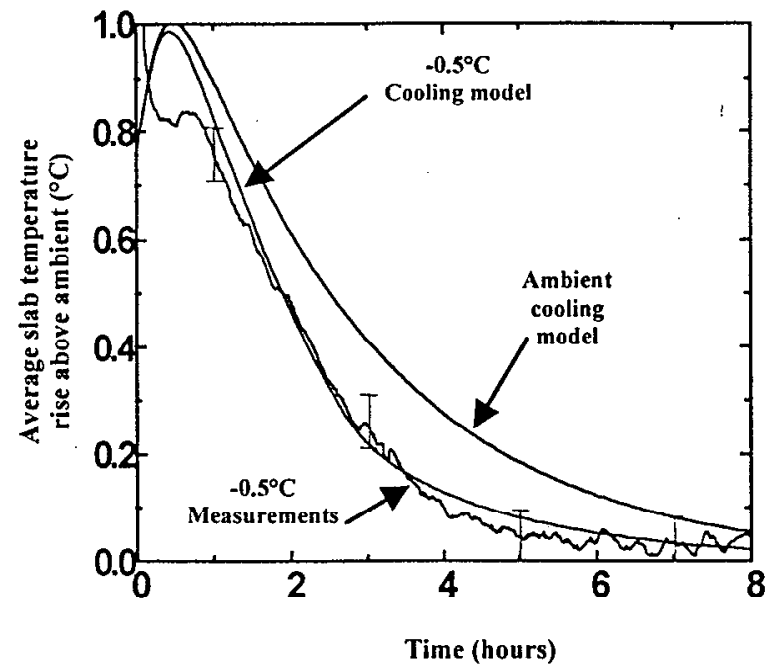

Fig. 10. Using slightly chilled $\left(-0.5^{\circ} \mathrm{C}\right)$ cooling gas accelerates slab thermal recovery rates.

\section{Conclusion and Summary}

Advances in amplifier technology developed for the NIF include a modular design and bottom-access carts to improve maintenance; features to improve storage efficiency that allow the size and cost of the power-condition system to be reduced; and active gas cooling to accelerate the laser shot rate. Further, gain, wavefront, and thermal-recovery measurements performed on the NIF prototype amplifier are consistent with meeting NIF performance requirements. These results show that the amplifier technology for the NIF is sufficiently developed for work on the final engineering design of the NIF amplifiers to proceed.

\section{Acknowledgements}

We thank John H. Campbell and his group for specifying and procuring the laser slabs used in the NIF prototype amplifiers.

We also thank Douglas W. Larson for designing the power conditioning system.

Work performed under the auspices of the U.S. Department of Energy by Lawrence Livermore National Laboratory under Contract no. W-7405-Eng-48. 


\section{References}

1. W. H. Lowdermilk, "Status of the National Ignition Facility Project," Second Annual Conference on Solid State Lasers for Application to Inertial Confinement Fusion, Vol 3047, SPIE, Bellingham, WA, p 16-37 (1997).

2. A. C. Erlandson, M. D. Rotter, D. N. Frank, and R. W. McCracken, "Design and Performance of the Beamlet Amplifiers," ICF Quarterly Report (5) 1, Lawrence Livermore National Laboratory, Livermore, CA, UCRLLR-105821-95-1, pp. 18-28 (1995).

3. W. F. Hagen, Laser Program Annual Report -1977, Lawrence Livermore National Laboratory, Livermore, CA, UCRL-50021-77, pp. 2-228 to 2-231 (1978).

4. H.T. Powell, A. C. Erlandson, K.S. Jancaitis, J.E. Murray, "Flashlamp Pumping of Nd:Glass Disk Amplifiers," High-Power Solid State Lasers and Applications, Vol 1277, SPIE, Bellingham, WA, p 103-120 (1990).

5. A. C. Erlandson, K.S. Jancaitis, R. W. McCracken, M.d. Rotter, "Gain Uniformity and Amplified Spontaneous Emission in Multisegment Amplifiers," ICF Quarterly Report 92-2, Lawrence Livermore National Laboratory, Livermore, CA, UCRL-LR-105821-92-3, pp. 105-114 (1992).

6. J. H. Kelly, M. J. Shoup III, M. D. Skeldon, and S. T. Bui, "Mechanical Design of 15- and 20-cm Clearaperture Disk Amplifiers for the OMEGA Upgrade, in Solid State Lasers III, edited by G. J. Quarles, Proceedings Vol. 1627, SPIE, Bellingham, WA, p 252-259 (1992).

7. A. C. Erlandson, H. Lambert, L.E. Zapata, L. Pedrotti, D.W. Larson, M.D. Rotter, W. J. Dallum, S. E. Seznec, G. LeTouze, E. Grebot, O. Carbourdin, J. C. Fornerod, and P. Bosch, "The effect of amplifier component maintenance on laser system availability and reliability for the US National Ignition Facility," Second Annual Conference on Solid State Lasers for Application to Inertial Confinement Fusion, Proceedings Vol 3047, SPIE, Bellingham, WA, p 16-37 (1997).

8. M. Takeda, H. Ina, and S. Kobayashi, "Fourier-transform method of fringe-pattern analysis for computer-based topography and interferometer," J. Opt. Soc. Am., 72, p 156-160 (1982).

9. H. T. Powell, A. C. Erlandson, and K. S. Jancaitis, "Characterization of High Power Flashlamps and Application to Nd:Glass Laser Pumping," Conference on Flashlamp-pumped Laser Technology, Proceedings Vol. 609, SPIE, Bellingham, WA, p 78-94 (1986). 